\title{
Wetsuits, body density and swimming performance
}

\author{
L. Cordain PhD and R. Kopriva MS \\ Department of Exercise and Sport Science, Colorado State University, USA
}

To determine the influence of body composition upon swimming performance with and without wetsuits, 14 competitive female swimmers (mean (s.d.) age, 19.9 (0.9) years) were measured for body density while wearing both wetsuits and normal swimsuits. Subjects swam 400 and $1500 \mathrm{~m}$ trials with and without wetsuits, randomly, over a 12-day period. Six subjects participated in an additional trial while wearing neoprene leg-bands fitted over the wetsuit. Mean (s.d.) subject density without and with wetsuits was $1.048(.009)$ and $1.021(.007) \mathrm{g} / \mathrm{ml}$ respectively. Wetsuits reduced $(P<0.05)$ swim times for the 400 $(-4.96 \%)$ and $1500 \mathrm{~m}$ swim $(-3.23 \%)$ compared with swimsuit trials. The neoprene bands increased $(P<0.05)$ swim times relative to swimsuit and wetsuit trials. With wetsuits, swim times were inversely $(P<0.05)$ related to density for the $400(r=-0.46)$ and $1500 \mathrm{~m}$ swim $(r=$ -0.54) suggesting that wetsuits increase performance by increasing buoyancy and that lean subjects benefit more from wearing wetsuits than do fatter subjects.

Keywords: Wetsuits, swimming performance, body composition

The triathlon, which consists of swimming, cycling and running, has become increasingly popular during the past 5 years. The swimming contest is often held in open water where low temperatures may present a hazard of hypothermia, and many athletes therefore wear wetsuits. Anecdotal evidence ${ }^{1,2}$ as well as the empirical study of Parsons and Day ${ }^{3}$ have indicated that swimming performance can be improved by wearing wetsuits. It has been suggested that the increased bouyancy brought about by the wetsuit allows swimmers to expend less energy on maintaining a horizontal swimming position, thereby freeing more effort for propulsion. Further, it has been shown that performance is superior in swimmers with greater lean body mass when compared with swimmers of similar fat mass but lower lean mass ${ }^{4}$. These data suggest that individuals with a low percentage of body fat tend to benefit more by wearing a wetsuit than their fatter counterparts. The intention of this study was to evaluate the influence of body composition on swimming performance while wetsuits were being worn.

Address for correspondence: Professor L. Cordain, Department of Exercise and Sport Science, Colorado State University, Fort Collins, CO 80523, USA

(C) 1991 Butterworth-Heinemann Ltd.

0306-3674/91/010031-03

\section{Methods}

Before starting this study, approval for the project was obtained from a University Committee on Human Research, and informed consent was secured from each subject. The subjects were 14 female, intercollegiate, Division I swimmers who were in the middle of their competitive season; their characteristics are shown in Table 1.

The wetsuits were Scott Tinley full-body, sleeveless, $3 \mathrm{~mm}$ thick triathlon wetsuits (manufactured by O'Neil Inc, Santa Cruz, California). Body densities both with and without wetsuits were determined using the hydrostatic weighing procedure ${ }^{5}$. During the wetsuit trials, a $31.9 \mathrm{~kg}$ belt was worn by all subjects so that they would submerge fully. Residual lung volumes were determined using the closedcircuit single breath, oxygen-dilution technique ${ }^{6}$. Body density was calculated using the following formula:

$$
D_{\mathrm{b}}=\frac{M_{\mathrm{a}}}{\frac{\left(M_{\mathrm{a}}-M_{\mathrm{w}}\right)}{D_{\mathrm{w}}}-\mathrm{RV}}
$$

$$
\text { where: } \begin{aligned}
D_{\mathrm{b}} & =\text { body density }(\mathrm{g} / \mathrm{ml}) \\
M_{\mathrm{a}} & =\text { subject body mass }(\mathrm{g}) \\
M_{\mathrm{w}} & =\text { subject underwater mass }(\mathrm{g}) \\
D_{\mathrm{w}} & =\text { water density }(\mathrm{g} / \mathrm{ml}) \\
\mathrm{RV} & =\text { residual lung volume }(\mathrm{ml})
\end{aligned}
$$

Subjects swam 400 and $1500 \mathrm{~m}$ trials with and without wetsuits, randomly, over a 12-day period at the same time of day. Touchpads were employed to record swim times to the nearest $0.01 \mathrm{~s}$. Six subjects swam an additional trial (three swam $400 \mathrm{~m}$; three swam $1500 \mathrm{~m}$ ) wearing neoprene calf-bands fitted over the wetsuit to give a further decrease in body density.

Table 1. Subject characteristics $(n=14)$

\begin{tabular}{lr}
\hline & Mean (s.d.) \\
\hline Age (years) & $19.9(0.9)$ \\
Height $(\mathrm{cm})$ & $168.8(6.6)$ \\
Weight $(\mathrm{kg})$ & $63.3(7.6)$ \\
Residual lung volume $(\mathrm{ml})$ & $1377(321)$ \\
Body density $(\mathrm{g} / \mathrm{ml})$ without wetsuits & $1.048(.009)$ \\
Body density $(\mathrm{g} / \mathrm{ml})$ & $1.021(.007)$ \\
\hline
\end{tabular}


Table 2. Swim times for the 400 and $1500 \mathrm{~m}$ trials with and without wetsuits

\begin{tabular}{lrr}
\hline Distance & Without wetsuits & With wetsuits \\
\hline $400 \mathrm{~m}$ & $4: 39.56(: 10.48)$ & $4: 25.64(: 10.11)$ \\
$1500 \mathrm{~m}$ & $18: 18.93(: 31.27)$ & $17: 43.75(: 47.51)$ \\
\hline
\end{tabular}

Values (min:sec) are mean (s.d.)

\section{Data analysis}

Differences between the wetsuit and swimsuit trials for both the distances were analysed using paired $t$-tests, whereas a two-way analysis of variance was used to determine differences in the sub-sample of swimmers wearing neoprene leg-bands in addition to the wetsuits. Duncan's multiple range test was employed for post-hoc analysis. Relationships between swim times and body densities with wetsuits were determined using Pearson's (r), as well as simple linear regression.

\section{Results}

Swim times were significantly $(P<0.001)$ reduced in both the 400 and $1500 \mathrm{~m}$ swim trials when the subjects were wearing the wetsuits (Table 2). Figures 1 and 2 depict the significant $(P<0.01)$ increase in swim times incurred with the addition of the neoprene leg-bands to the wetsuits for both the 400 and $1500 \mathrm{~m}$ trials. Significant relationships $(P<0.05)$ were demonstrated both between body density with the wetsuit and the $400 \mathrm{~m}$ swim $(r=-0.46)$ and the $1500 \mathrm{~m}$ swim $(r=-0.54)$ (Figures 3 and 4$)$.

\section{Discussion}

The present data are consistent with those of Parsons and Day $^{3}$ in that the addition of wetsuits enhanced swimming performance by a similar magnitude. These reductions in swim times with wetsuits $(-4.96 \%$ for the $400 \mathrm{~m}$ swim, and $-3.23 \%$ for the $1500 \mathrm{~m}$ swim) would represent an $18.6 \mathrm{~m}$ difference in the $400 \mathrm{~m}$ swim and a $25.7 \mathrm{~m}$ difference in the $1500 \mathrm{~m}$ swim. Both of these differences could certainly account for winning and losing performances in the triathlon. It would seem likely that participants without wetsuits would be at a distinct disadvantage.

Our results (Figures 3 and 4) showed that leaner subjects tended to swim faster while wearing wetsuits, whereas no such relationship existed when the wetsuits were not worn. These relationships suggest that leaner subjects tend to benefit more by wearing wetsuits than do their fatter counterparts. Stager et al. $^{4}$ were able to demonstrate that when fat body masses were similar in female swimmers, those swimmers with the greater lean body mass tended to swim faster for a $100 \mathrm{~m}$ swim. That study as well as the present study corroborate the notion expressed by Parsons and Day ${ }^{3}$ that wetsuits enhance swimming performance mainly by increasing buoyancy thereby allowing more energy to be used for propulsive action rather than for maintaining the horizontal position.

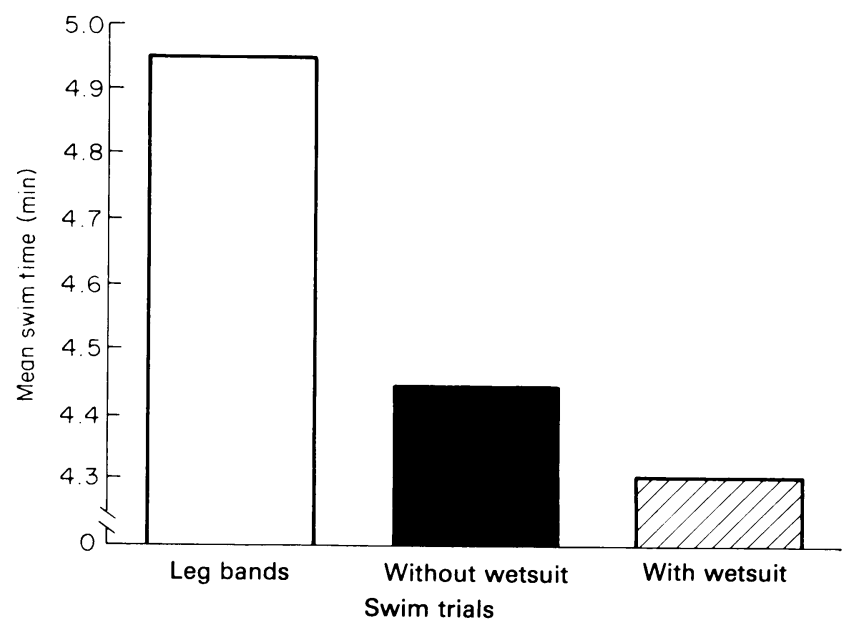

Figure 1. Comparisons of swimming performances for the $400 \mathrm{~m}$ trials. $\square, n=3 ; \square, n=14 ; \bigotimes, n=14$

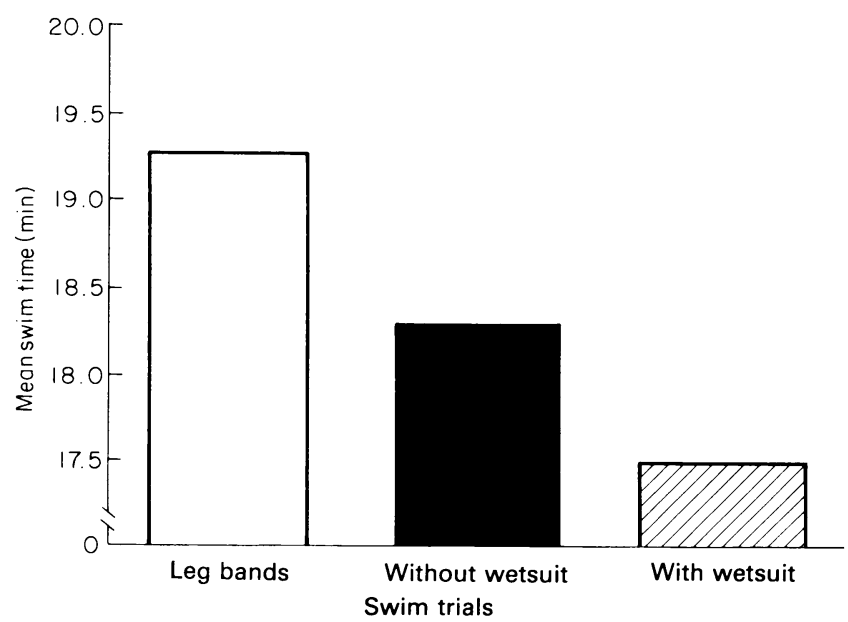

Figure 2. Comparisons of swimming performances for the $1500 \mathrm{~m}$ trials. $\square, n=3 ; \square, n=14 ; \square \mathbb{}, n=14$

We postulated that perhaps even further reductions in swim times would occur with further increases in (swimmer plus wetsuit) densities. To accomplish this, we fitted neoprene bands over the wetsuit at the calf. The results as shown in Figures 1 and 2 clearly indicate that the bands hindered performance. Subjects complained that the neoprene leg-bands caused their legs to be 'too high' in the water. It is likely that the bands placed the feet and legs in a higher than optimal position in the water which perhaps negated the propulsive effects of the kick. It is unclear how further changes in (swimmer plus wetsuit) density in other body parts would affect performance.

The present trials were conducted in a 25-yard $(22.86 \mathrm{~m})$ swimming pool with a water temperature varying between 26 and $28^{\circ} \mathrm{C}$. A consistent complaint by the subjects when swimming both distances was of 'being so hot'. Loudon ${ }^{2}$ has suggested that optimal gains in performance occur with wetsuits when the water temperature is cool $\left(17.7^{\circ} \mathrm{C}\right)$. Perhaps the decrease in time over the $1500 \mathrm{~m}$ trial was not as great as that for the $400 \mathrm{~m}$ trial because of a reduced ability of the body to dissipate heat for the longer distance. 


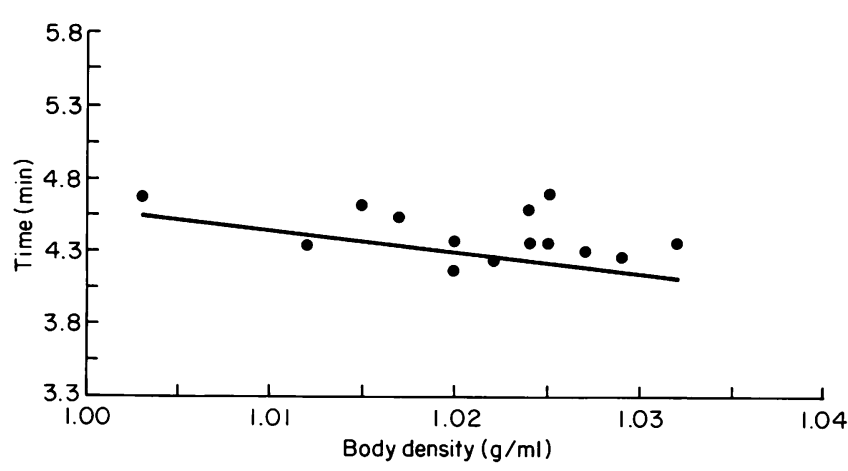

Figure 3. Relationships of swimming performances while wearing the wetsuit to body densities for the $400 \mathrm{~m}$ trial. $Y=15.5-10.85(x) ; r=-0.46 ;$ standard error of estimate $=0.16$

\section{Conclusion}

Wetsuits enhance swimming performance by directly increasing buoyancy, thereby allowing more effort to be expended in propulsive movement. Leaner subjects tend to benefit more from the wetsuit than do fatter subjects. Further research is warranted in determining optimal wetsuit thickness for the various body segments, so that buoyancy can be enhanced without alterations in the biomechanics of the swimming stroke.

\section{Acknowledgements}

Wetsuits used in this study were donated by the $O^{\prime}$ Neil Corporation, Santa Cruz, CA 95063-6300, USA.

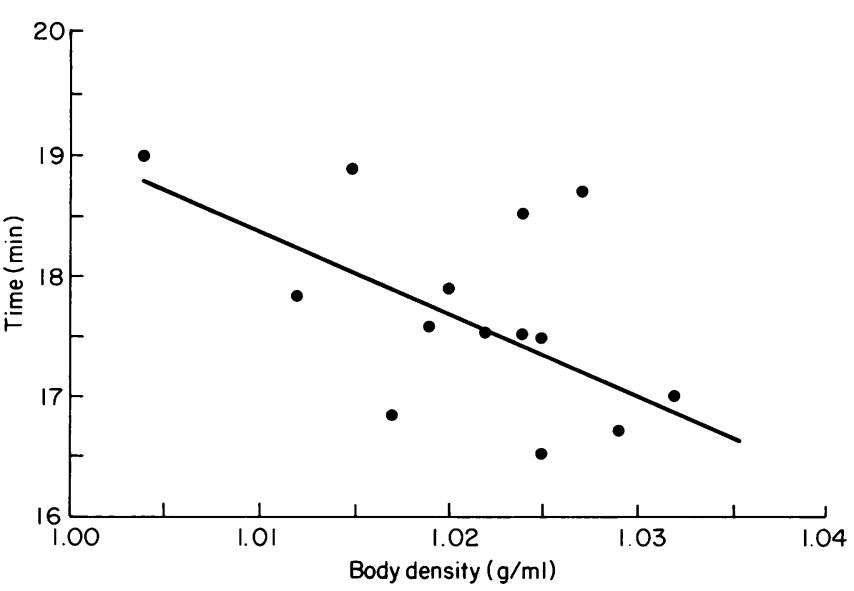

Figure 4. Relationships of swimming performances while wearing the wetsuit to body densities for the $1500 \mathrm{~m}$ trial. $Y=79.32-60.32(x) ; r=-0.54 ;$ standard error of estimate $=0.72$

\section{References}

1 Harper D. Wet behind the seams. Triathlete 1985; 28: 14-5

2 Loudon B. The speed suit. Triathlete 1987; 46: 22-3

3 Parsons L, Day J. Do wetsuits affect swimming speed? $\mathrm{Br} J$ Sports Med 1986; 20: 129-31

4 Stager JM, Cordain L, Becker TJ. Relationship of body composition to swimming performance in female swimmers. $J$ Swim Res 1984; 1: 21-6

5 Katch F, Michael E, Horvath SM. Estimation of body volume by underwater weighing: description of a simple method. $J$ Appl Physiol 1967; 23: 811-13

6 Wilmore J. A simplified method for determination of residual lung volumes. J Appl Physiol 1969; 27: 96-100 